\title{
Lifestyle impact and the biology of the human scrotum Richard Ivell*
}

\author{
Address: Research Centre for Reproductive Health, and School of Molecular and Biomedical Science, University of Adelaide, SA 5005, Australia \\ Email: Richard Ivell* - richard.ivell@adelaide.edu.au \\ * Corresponding author
}

Published: 20 April 2007

Reproductive Biology and Endocrinology 2007, 5:15 doi:10.1/86/1477-7827-5-15

This article is available from: http://www.rbej.com/content/5/I//5

(c) 2007 Ivell; licensee BioMed Central Ltd.

This is an Open Access article distributed under the terms of the Creative Commons Attribution License (http://creativecommons.org/licenses/by/2.0), which permits unrestricted use, distribution, and reproduction in any medium, provided the original work is properly cited.
Received: 8 March 2007

Accepted: 20 April 2007

\begin{abstract}
The possession of a scrotum to contain the male gonads is a characteristic feature of almost all mammals, and appears to have evolved to allow the testes and epididymis to be exposed to a temperature a few degrees below that of core body temperature. Analysis of cryptorchid patients, and those with varicocele suggest that mild scrotal warming can be detrimental to sperm production, partly by effects on the stem cell population, and partly by effects on later stages of spermatogenesis and sperm maturation. Recent studies on the effects of clothing and lifestyle emphasize that these can also lead to chronically elevated scrotal temperatures. In particular, the wearing of nappies by infants is a cause for concern in this regard. Together all of the evidence indirectly supports the view that lifestyle factors in addition to other genetic and environmental influences could be contributing to the secular trend in declining male reproductive parameters. The challenge will be to provide relevant and targeted experimental results to support or refute the currently circumstantial evidence.
\end{abstract}

\section{Background}

The exteriorization of the male gonads in a special sac called the scrotum is a uniquely mammalian feature, and one that at first glance requires some explanation. Surely, a trait that would place all of the genetic material essential for procreation in such an exposed situation, rather than protecting it deep within the organism (e.g. like the ovaries) must have some important selective advantage; otherwise why could it evolve and why has it not been selected against. The most plausible evolutionary explanation relates to the requirement of spermatogenesis for an optimum temperature lower than core abdominal temperature [1]. Certainly, the temporary exposure of the adult testes to mild warming (abdominal temperature) leads to marked disruption of spermatogenesis and/or male fertility [2,3]. Testicular descent into a scrotum evolved probably more than 150 million years ago concurrently with the acquisition by ancestral mammals of a regulated hyperthermia [1], which provided the abdominal organs with a controlled, stable body temperature of ca. $36-38^{\circ} \mathrm{C}$. It is notable that in many mammals which have reverted to having abdominal testes, either there is a specialized blood supply acting as a heat exchanger to cool the abdominal gonad (e.g. whales), or the core temperature is itself relatively low $34-36^{\circ} \mathrm{C}$ (e.g. some insectivores) [1]. Although elephants appear to have abdominal testes as a primitive trait, there is recent evidence to suggest that they may have had an aquatic origin in the distant past [4], possibly at a time of early mammalian radiation, when the scrotal trait was not fully established in all mammalian lineages.

Why a reduced scrotal temperature has selective advantage is not immediately clear, particularly since a number of animals (such as elephants, hyraxes and reptiles) appear to survive and reproduce with abdominal testes. It is gen- 
erally assumed that the lower temperature leads to reduced rates of oxidative DNA damage and hence to fewer mutations in resulting sperm $[1,5]$. A second concept relates to the fact that sperm are stored, often over many days or weeks, in the epididymis, particularly the cauda epididymis, which resides at the coolest location within the scrotum [6]. A lower temperature would lead to reduced metabolic rate and oxidative damage in these stored sperm. Linking these concepts is one that suggests that the lower temperature provides a selection process for the best adapted sperm able to confront the metabolic stresses of ejaculation and fertilization [7]. Subsequently, in a number of species, the exteriorized testes in their scrotal sacs have acquired behavioural importance as signals of sexual prowess, leading to the evolution of exaggerated colours and dimensions. In some species, such as dogs, the scrotum can become hairless and acquire a dark coloration to aid heat radiation (Fig. 1), emphasizing again the physiological importance of a cool scrotum. Besides coloration, the usual mechanism of scrotal cooling in high ambient temperatures appears to be by sweat evaporation from the scrotal surface, though the study by Yaeram et al. [3] with mice suggests that even very mild elevation of ambient temperature, in this case exposure to $36^{\circ} \mathrm{C}$ for 12 hours per day, can impair spermatogenesis.

\section{Scrotal pathology and temperature}

There are two common pathologies associated with testicular heating: cryptorchidism and varicocele. In cryptorchidism, due to a variety of causes, one or both testes may be retained within the abdominal cavity or within the inguinal canal rather than descending normally into the scrotum, which in humans logically occurs at birth. Testicular descent in humans is separated into two major phases $[8,9]$. The first phase, which occurs during pregnancy, is characterized by a relocation of the testes from a more dorsal perirenal position to one in the inguinal region of the body cavity. This is achieved by dissolution, under the influence of androgens, of the cranial suspensory ligament securing the fetal testes dorsally, and most importantly a growth and development of the ventrally located gubernacular ligament [9]. This is the result of a combination of androgen action, some effect of the peptide AntiMullerian Hormone (AMH), and most importantly the relaxin-like male hormone, Insulin-like peptide 3 (INSL3) [9-11]. The role of AMH in testicular descent is unclear, whilst there appears to be a small in vitro effect on guber-

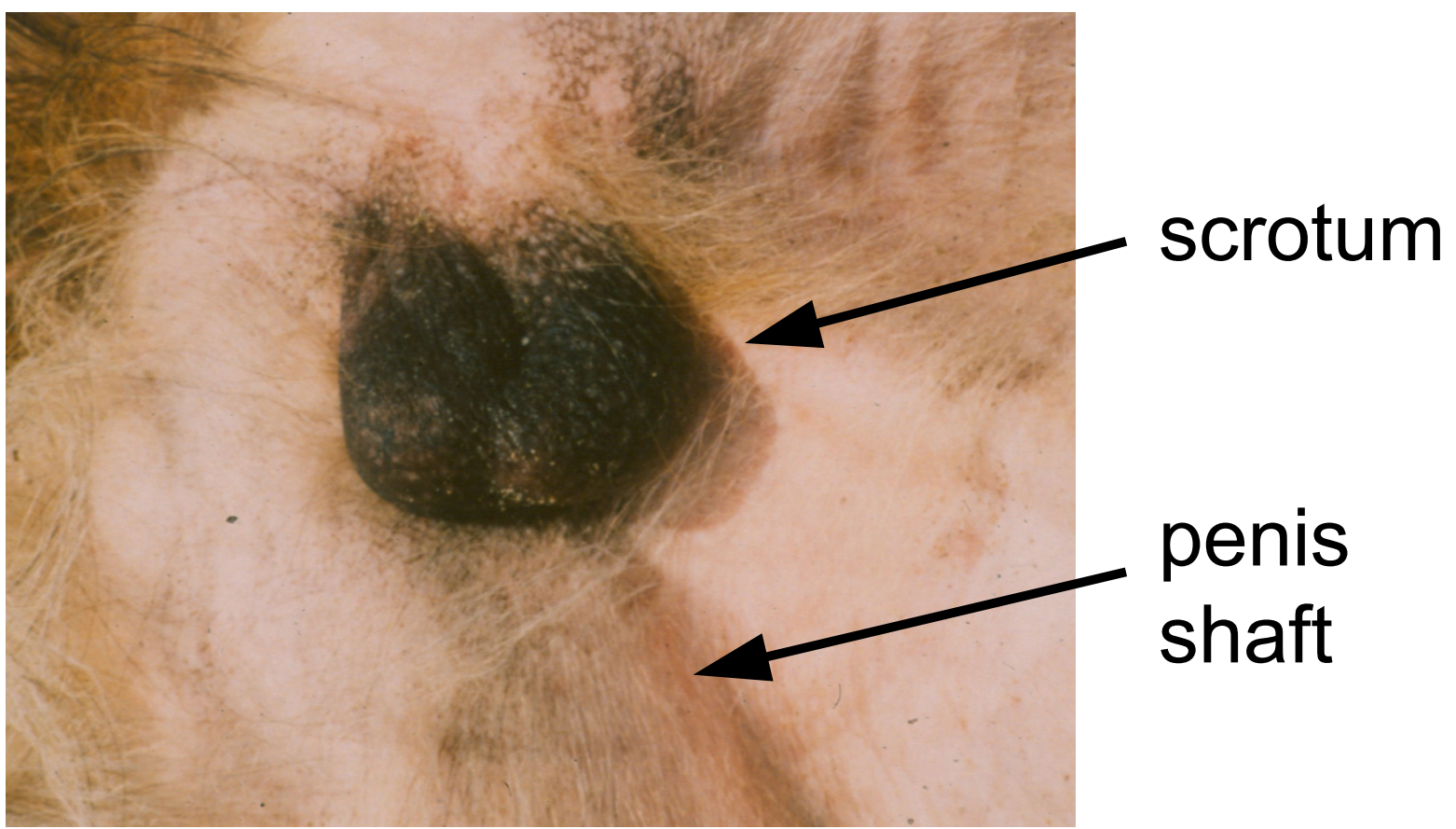

\section{Figure I}

Scrotum of a dog to illustrate natural dark coloration and hairlessness to encourage heat loss. The dark colour also probably protects from UV irradiation. 
nacular growth [11], most studies show no influence of this hormone $[10,12]$. How the testes enter the scrotum is not well understood, though a considerable body of evidence shows that the majority of children whose testes are descended into the inguinal region, but cannot progress further, can be successfully treated by stimulating the hypothalamo-pituitary-gonadal axis, either by GnRH (gonadotropin releasing hormone) analogues or by hCG (human chorionic gonadotropin) $[8,13,14]$. This is usually interpreted to imply that also this phase is under androgen control, but since this treatment serves to stimulate Leydig cell differentiation and activity, it might also imply that other Leydig cell products, of which INSL3 is one, might also be involved.

The consequences of cryptorchidism are now well established. A failure to descend the testes in early childhood leads to reduced testicular function, particularly reduced sperm production and infertility $[14,15]$. More significantly, there is also a correlation with the development of testicular cancer [16]. A large number of studies in animals with induced cryptorchidism, or local testicular heating as adults, show that the process of spermatogenesis is exquisitely sensitive to temperature (Fig. 2), with increased germ cell apoptosis (mostly spermatocytes and spermatids) a consequence of only relatively short periods of mild testicular heating (reviewed in [2]). The neonatal and prepubertal periods were previously considered relatively inert, so that a surgical correction of an abdominal testis (orchidopexy) could be timed for any age prior to the onset of puberty and the commencement of spermatogenesis. Recent observations show that this is incorrect, and that abdominal temperature can markedly influence the number of spermatogonial stem cells that are available to generate all sperm in later life [20]. It appears that there is an inverse relationship between the number of germ cell stem cells $\left(A_{\text {dark }}\right.$ spermatogonia) in testis biopsies and the age at which orchidopexy was performed [20], and as a consequence there is a relationship also to sperm production in the later adult. The earlier the testes reach the scrotum after birth, the better the chances of full spermatogenesis as an adult.

The detailed mechanisms operating at a cellular or molecular level are unclear. This is partly due to the fact that it is not possible to distinguish between effects due to unnatural heating of the postnatal testis, and factors which led to cryptorchidism in the first place. So, for example, whilst it appears that $A_{d a r k}$ spermatogonia are negatively affected by postnatal warming, these cells or their progenitor gonocytes may also be targets of the same endocrine disruptors that can affect male differentiation in utero, leading also to gonocyte transformation and the formation of carcinoma-in-situ (CIS) cells, which are the seeds of later seminomas [21]. Similarly, a common feature of the peri- natal cryptorchid testis are poorly functioning Leydig cells, and hence reduced androgen levels in the so-called perinatal "minipuberty" [22]. It is known that endocrine disruptors such as phthalates can lead to both reduced Leydig cell function and to cryptorchidism [23-25]. Therefore, at this stage in time, we cannot state what are pure effects due only to unnatural testicular heating in early childhood, and what may be effects linked to the original cause of the cryptorchidism.

To complicate the issue further, there may be circumstances where an increase of testicular temperature to that of the abdomen appears to be advantageous. For example, in the $j s d / j s d$ mouse, which has impaired spermatogenesis due to a mutation in the mUtp $14 b$ gene, retention of the testis in the abdomen actually rescues the arrest of spermatogonial differentiation, thus partly restoring spermatogenesis [26]. However, more extensive studies show that the higher temperature is actually causing a subtle androgen-control system to be down-regulated, and that the activated androgen receptor is mediating the arrest of spermatogenesis in this mutant [27]. Thus this mutant does not contradict the generally negative effects of abdominal temperature on testis function.

In varicocele, there is large varicose distension of venous blood vessels within the scrotum, usually associated with increased blood flow $[28,29]$. One physiological consequence of this, besides increased oxidative stress, is also increased local temperature of the testis, and hence impairment of spermatogenesis [28-31].

\section{Lifestyle factors and scrotal function}

It has long been a source of investigation and speculation that the adoption of certain styles of clothing and posture can influence testicular function, and in particular spermatogenesis. The importance of clothing style and its tightness remains controversial (reviewed in $[32,33]$ ), as also is the influence of hot baths, saunas, etc. However, given that the natural cooling methods for the scrotum rely on sweating and vasomotor changes [34], it is now very clear that clothing in combination with behaviour or posture can have significant effects. Normal scrotal temperature (the external surface of the scrotum) is approximately $34^{\circ} \mathrm{C}$ in a normally clothed man walking about or maintaining a loose stance, and it has been estimated that testicular temperature within the scrotum is between 0.1 and $0.6^{\circ} \mathrm{C}$ higher than this $[32,35,36]$. Clothing itself appears to contribute about $0.5-1.0^{\circ} \mathrm{C}$ [37], compared to being naked. Clothed and sitting down with thighs apart raises scrotal temperature to about $35 \mathrm{C}$, whereas sitting with thighs together quickly allows scrotal temperature to rise to above $36 \mathrm{C}$, i.e. to abdominal temperature within the testis [36]. Several studies have now shown that men with predominantly sedentary occupations [36], or who 


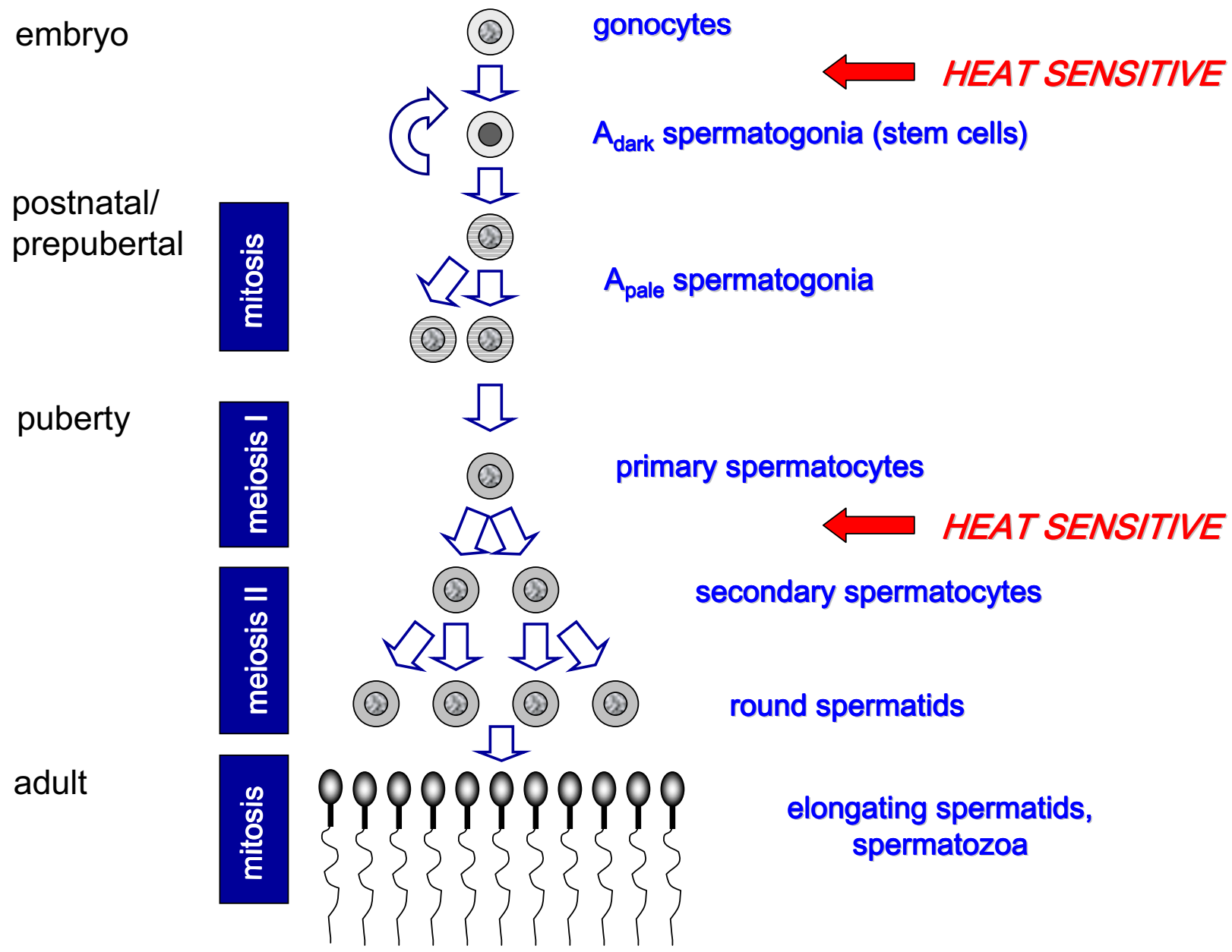

Figure 2

Diagram to illustrate spermatogenesis in the human and those steps which appear to be particularly heat-sensitive. It is largely unclear how a small increase in temperature induces apoptosis. In the adult, both germ cells and Sertoli cells appear to be responsive to heat and show changes in the expression of, for example, heat shock proteins [17-19].

spend considerable time driving a vehicle [38,39], have higher average scrotal temperatures and consequently lower average sperm production or reduced fertility. Another situation where scrotal temperatures become elevated is during sleep, when bedclothes and lack of movement prevent ventilation. Men with oligozoospermia or oligoasthenozoospermia who were allowed to sleep with a small apparatus which permitted nocturnal scrotal cooling showed significant improvements in semen quality over a period of 12 weeks $[32,33]$. This time is required to allow positive effects on all stages of spermatogenesis, including stem cells to become manifest in the ejaculate. Taken together, these studies all indicate that a more sedentary lifestyle can and most likely does cause a significant impairment in sperm production and quality.
All of the preceding studies relate to testis function in the adult. There is far less known about the impact of lifestyle factors on the important prepubertal and perinatal stages of reproductive development. This is the period when the endocrine axes become established and the functionality of individual cell components of the testis is determined. Besides the generally negative effects of sedentary habits on children in the context of their later developing symptoms of obesity and metabolic syndrome (e.g. [40]), continual over-heating of the testes are likely to impact also on the establishment of spermatogenesis during adolescence. Possibly more significant than this, however, are the consequences on reproductive parameters of the wearing of nappies (diapers) in infancy. Nappy use leads to a long-term increase in scrotal temperature of 1-2 C, com- 
pared to air-exposure $[41,42]$. There appears to be little difference between the use of modern disposable nappies and old-fashioned cloth nappies used together with a plastic cover. If these become wet or soiled, then a further increase in scrotal temperature may be recorded [42]. Dry cloth nappies without any covering only appear to have a small effect on scrotal temperature [42]. Babies are often sedentary or asleep for long periods and nappies may become soiled or wet for much of this time. Nappy usage can extend for several years at a time when the testes may be establishing their reproductive potential. If we consider the risks to the $A_{\text {dark }}$ spermatogonial stem cell population that may be incurred by a delay in surgically descending cryptorchid testes (see above), then the usage of modern disposable nappies may also be incurring similar long term consequences to the reproductive potential of future men. Since cryptorchidism is associated with testicular cancer, one recent study has looked at whether nappywearing has consequences in terms of testicular cancer risk [43]. In this retrospective study, no association was found. However, as mentioned above, there is no evidence to show that it is testicular heating rather than some common intrauterine cause which leads to CIS cells and resultant testicular cancer.

\section{The role of the epididymis}

In most mammals, sperm leaving the testis are unable to fertilize an oocyte, but first need to undergo a maturation process, which occurs in the epididymis. This is also likely to be the case in humans. The epididymis comprises a highly specialized tubular structure subdivided essentially into three major regions: caput, corpus and cauda. Sperm leave the testis via the excurrent ducts and enter first the initial segment of the caput, followed by the caput proper, and subsequently the corpus and cauda epididymis. The nature of the epididymal maturation process is unclear, though certainly involves the modification of the sperm membrane by interaction with epididymal products, and the acquisition of the ability to become capacitated (reviewed in [44]). Differential cloning and expression studies show that the epithelium of the epididymis produces large amounts of highly specific gene products, which are regionally specialized, and many of which interact with and modify the surface of sperm in transit. Anatomically, the cauda epididymis is located in the most ventral and coolest region of the scrotum. This is the region where sperm are stored for periods of days to weeks, and has given rise to the notion that one of the reasons for the evolution of the scrotum was to provide optimal conditions for sperm storage [6]. Using epididymal epithelial cell cultures, it was shown that one of the major gene products of the epididymis, the major sperm surface antigen CD52, was almost completely and specifically inhibited by switching culture temperature from scrotal temperature $\left(33^{\circ} \mathrm{C}\right)$ to abdominal temperature $\left(37^{\circ} \mathrm{C}\right)$
(Fig. 3) [45]. This experiment showed that the temperature sensing mechanisms regulating epididymal gene expression are exquisitely sensitive, and that probably artificial elevation of scrotal temperature is likely to have negative effects not only on spermatogenesis in the testis but also on sperm maturation and storage processes within the epididymis.

All studies to date relate to experiments carried out in adult-type systems. There is no information about effects of scrotal temperature on the early development of the epididymis or its functions, or whether long-term exposure to higher temperatures early in life could elicit adaptive processes of benefit in adulthood.

\section{Conclusions and consequences}

There is currently worldwide concern over possible effects of endocrine disrupting agents, with much evidence pointing to an impact by such xenobiotics on the developing fetus in utero. In the context of male reproduction there appears to be a recognized association between xenobiotic exposure and traits such as hypospadias, cryptorchidism, CIS and testicular cancer, and reduced anogenital distance $[25,46]$. In animal experiments, where rats have been given high doses of phthalates, this extends also to reduced adult sperm production. Whether xenobiotic exposure of the male fetus is responsible for the sometimes considerably reduced human sperm counts in some European countries is still debatable. A key feature of traits such as low sperm counts is that the trends are consistently increasing over long periods of time, indicating clear cohort effects, and regionally different rates of change. Together, these features point to an environmental influence, which is associated with increased industrialization. More recently, a similar trend has been reported in the context of the Massachussetts male ageing study, for the total circulating testosterone. This appears to be declining in ageing men in a cohort-dependent manner, which is independent of other lifestyle confounders [47].

The accumulated evidence is highly compelling that the scrotum has evolved in order to provide a local environment for sperm production, maturation and storage that is several degrees cooler than core body temperature. A failure to cool the scrotum adequately appears to be associated in the adult with impaired spermatogenesis, in young boys possibly also to a reduced gonadal stem cell population. Lifestyle factors such as clothing, posture, sedentary behaviour, and the wearing of nappies by babies all seem to predicate a worsening of male reproductive parameters, possibly contributing amongst other factors to the secular trends observed in sperm counts across the globe. 


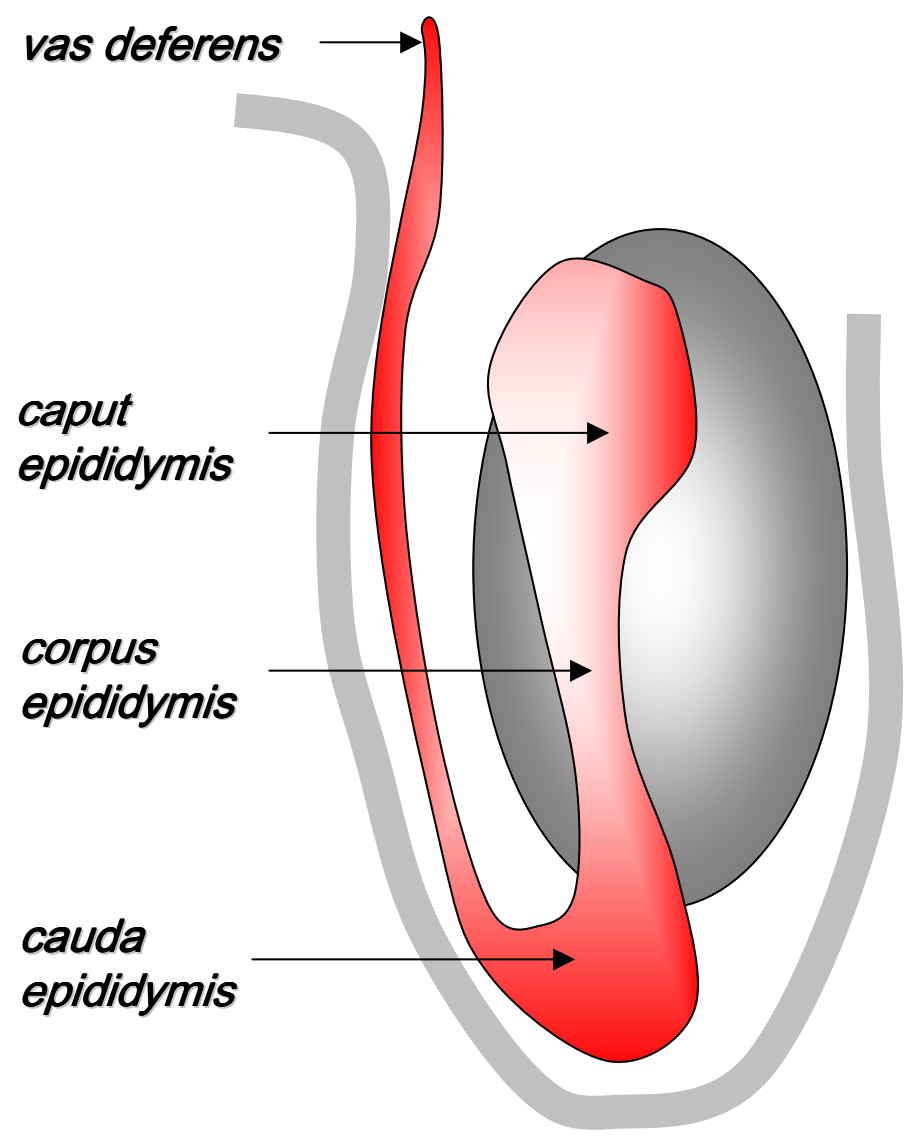

primary epididymal cell culture

\author{
$\begin{array}{llllll}1 & 2 & 3 & 4 & 5 & 6\end{array}$ \\ $33^{\circ} 37^{\circ} 33^{\circ} 37^{\circ} 33^{\circ} 37^{\circ} 33^{\circ} 37^{\circ} 33^{\circ} 37^{\circ} 33^{\circ} 37^{\circ}$
}

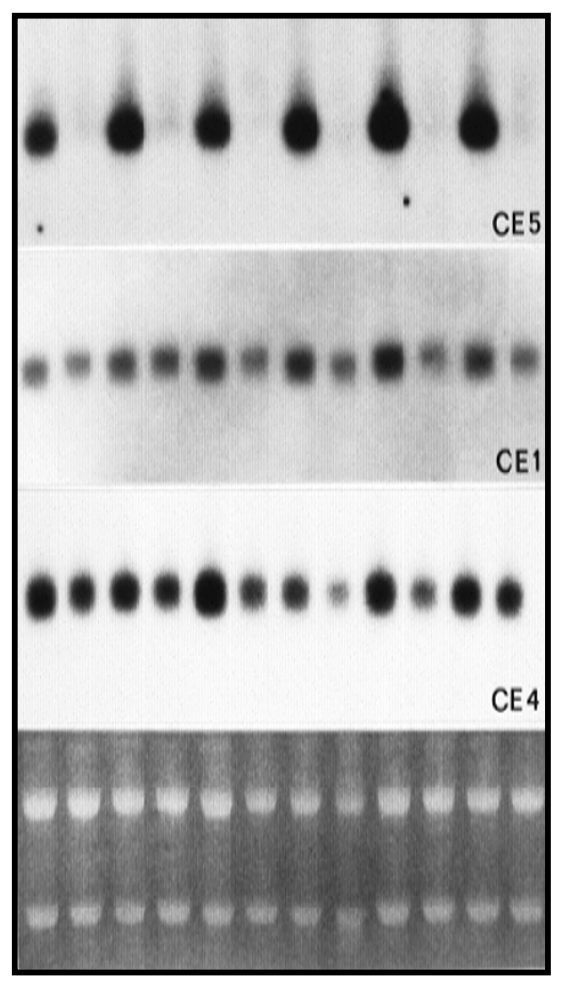

\title{
Figure 3
}

Effect of heating on epididymal cell function. The left panel indicates the gross anatomy of the epididymis within the scrotum. Sperm exit the testis via the excurrent ducts, first entering the initial segment of the epididymis, before traversing successively through the caput, corpus and cauda epididymis, where successively different sets of epidiymal gene products interact with the transiting sperm. The right panel shows northern hybridizations of mRNA extracted from six different independent epididymal epithelial cell cultures subjected to either scrotal (33 C) or abdominal (37 C) culture temperatures. Panels indicate from top to bottom gene transcripts for the epididymis-specific CE5 (CD52; the principal sperm-surface antigen), CEI (also known as the lipocalin Niemann-Pick C2), and CE4 (a putative extracellular protease inhibitor) genes. The bottom panel is a loading control indicating by ethidium bromide staining the intensities of the I8S and 28S ribosomal RNA bands. Reproduced with permission from Pera et al. [45] (Copyright 1996, The Endocrine Society).

However, most of the evidence is circumstantial, and at least one author [48] has suggested that a direct proof of such effects remains "untestable" in the context of evidence-based medicine. The reasons for this are largely due to the uniqueness of the human situation. There are few experimental animal models which can be considered comparable or appropriate for the human. We undergo a period of relative testicular quiescence of more than 8 years from birth until the beginnings of puberty, when possible negative influences on scrotal temperature could impact subtly upon stem cell populations, as well as dur- ing the whole adult lifespan. Rodent models exhibit a comparable prepubertal period of barely 2 weeks, whilst other models such as sheep or dogs can extend this to a period of up to 2-3 months. These are time periods which are biologically not comparable. Add to this that the human species appears to have a fundamental, genetic impairment of spermatogenesis compared to domestic and laboratory species which have been bred for fertility and fecundity. There are indeed a number of mutations in fertility genes in the human, which are considered important in other species $[49,50]$, suggesting that humans as a 
species are essentially subfertile, and thus more predisposed to subtle negative environmental influences. Epidemiological studies also appear to be highly problematic, largely because of an absence of appropriate matched control groups, i.e. who do not wear clothes, or wear no nappies of any kind, etc.

We are therefore confronted with a difficult problem. Until direct rather than circumstantial evidence can be produced, current lifestyle habits and conveniences will prevail, probably to the detriment of our reproductive capacity. This is the core tenet of evidence-based medicine. The challenge therefore must be met to devise the experiments which will convincingly provide that evidence or refute the possibility.

\section{Competing interests}

The author(s) declare that they have no competing interests.

\section{Acknowledgements}

I should like to acknowledge the friendly support of my colleagues in the Research Centre for Reproductive Health, and especially the inspiring discussions with Professor Brian Setchell, who has pioneered research into heating effects of the testis. I am also indebted to the National Health and Medical Research Council of Australia, and the Australian Research Council for funding support of my research.

\section{References}

I. Werdelin L, Nilsonne A: The evolution of the scrotum and testicular descent in mammals: a phylogenetic view. J Theor Biol 1999, 196:61-72.

2. Setchell BP: The Parkes lecture. Heat and the testis. J Reprod Fertil 1998, I I 4:179-194.

3. Yaeram J, Setchell BP, Maddocks S: Effect of heat stress on the fertility of male mice in vivo and in vitro. Reprod Fertil Dev 2006, 18:647-653.

4. Gaeth AP, Short RV, Renfree MB: The developing renal, reproductive, and respiratory systems of the African elephant suggest an aquatic ancestry. Proc Natl Acad Sci USA 1999, 96:5555-5558.

5. Short RV: The testis: the witness of the mating system, the site of mutation and the engine of desire. Acta Paediatr Suppl 1997, 422:3-7.

6. Bedford JM: Anatomical evidence for the epididymis as the prime mover in the evolution of the scrotum. Am J Anat 1978, 1 52:483-507.

7. Freeman $S$ : The evolution of the scrotum: a new hypothesis. J Theor Biol 1990, I 45:429-445.

8. Hutson JM, Hasthorpe S, Heyns CF: Anatomical and functional aspects of testicular descent and cryptorchidism. Endocr Rev 1997, 18:259-280.

9. Ivell R, Hartung S: The molecular basis of cryptorchidism. Mol Hum Reprod 2003, 9:175-181.

10. Emmen JM, McKuskey A, Adham IM, Engel W, Grootegoed JA, Brinkmann AO: Hormonal control of gubernaculums development during testis descent: gubernaculums outgrowth in vitro requires both insulin-like factor and androgen. Endocrinology 2000, | $41: 4720-4727$.

II. Kubota Y, Temelcos C, Bathgate RA, Smith KJ, Scott D, Zhao C, Hutson JM: The role of insulin 3, testosterone, Mullerian inhibiting substance and relaxin in rat gubernacular growth. Mol Hum Reprod 2002, 8:900-905.

12. Lyet L, Vigier B, van der Schoot P: Anti-mullerian hormone in relation to the growth and differentiation of the gubernacular primordia in mice. J Reprod Fertil 1996, 108:28I-288.
13. Giannopoulos MF, Vlachakis IG, Charissis GC: 13 years' experience with the combined hormonal therapy of cryptorchidism. Horm Res 200I, 55:33-37.

14. Hadziselimovic F: Cryptorchidism, its impact on male fertility. Eur Urol 2002, $41: 121-123$.

15. Rusnack SL, Wu HY, Huff DS, Snyder HM 3rd, Carr MC, Bellah RD, Zderic SA, Canning DA: Testis histopathology in boys with cryptorchidism correlates with future fertility potential. J Urol 2003, 169:659-662.

16. Dieckmann KP, Skakkebaek NE: Carcinoma in situ of the testis: a review of biological and clinical features. Int J Cancer 1999, 83:8I5-822.

17. Kumagai J, Fukuda J, Kodama H, Murata M, Kawamura K, Itoh H, Tanaka T: Germ cell specific heat shock protein 105 binds to p53 in a temperature-senistive manner in rat testis. Eur J Biochem 2000, 267:3073-3078.

18. Hirai K, Sasaki H, Yamamoto H, Sakamoto H, Kubota Y, Kakizoe T, Terada M, Ochiya T: HST-I/FGF-4 protects male germ cells from apoptosis under heat-stress condition. Exp Cell Res 2004, 294:77-85.

19. Zhang XS, Lue YH, Guo SH, Yuan JX, Hu ZY, Han CS, Hikim AP, Swedloff RS, Wang C, Liu YX: Expression of HSP I 05 and HSP60 during germ cell apoptosis in the heat-treated testes of adult cynomolgus monkeys (macaca fascicularis). Front Biosci 2005, I0:3||0-3|2|.

20. Hadziselimovic F, Herzog B: The importance of both an early orchidopexy and germ cell maturation for fertility. Lancet 200I, 358: II I56-II57.

21. Skakkebaek NE, Rajpert De Meyts E, Main KM: Testicular dysgenesis syndrome an increasingly common developmental disorder with environmental aspects. Hum Reprod 200I, 16:972-978.

22. Hadziselimovic F, Zivkovic D, Bica DT, Emmons LR: The importance of mini-puberty for fertility in cryptorchidism. J Urol 2005, 174:1536-1539.

23. McKinnell C, Sharpe RM, Mahood K, Hallmark N, Scott H, Ivell R, Staub C, Jegou B, Haag F, Koch-Nolte F, Hartung S: Expression of insulin-like factor 3 protein in the rat testis during fetal and postnatal development and in relation to cryptorchidism induced by in utero exposure to di(n-Butyl)phthalate. Endocrinology 2005, 146:4536-4544.

24. Main KM, Mortensen GK, Kaleva MM, Boisen KA, Damgaard IN, Chellakooty M, Schmidt IM, Suomi AM, Virtanen HE, Petersen DV, Andersson AM, Toppari J, Skakkebaek NE: Human breast milk contamination with phthalates and alterations of endogenous reproductive hormones in infants three months of age. Environ Health Perspect 2006, I | 4:270-276.

25. Foster PM: Disruption of reproductive development in male rat offspring following in utero exposure to phthalate esters. Int J Androl 2006, 29: I 40-I47.

26. Shetty G, Weng CCY: Cryptorchidism rescues spermatogonial differentiation in juvenile spermatogonial depletion (Jsd) mice. Endocrinology 2004, I 45: | 26- I33.

27. Shetty G, Weng CCY, Porter KL, Zhang Z, Pakarinen P, Kumar TR, Meistrich ML: Spermatogonial differentiation in juvenile spermatogonial depletion (jsd) mice with androgen receptor or follicle-stimulating hormone mutations. Endocrinology 2006, 147:3563-3570.

28. Turner TT: The study of varicocele through the use of animal models. Hum Reprod Update 200I, 7:78-84.

29. Schoor RA, Elhanbly SM, Niederberger C: The pathophysiology of varicocele-associated male infertility. Curr Urol Rep 200I, 2:432-436.

30. Ali Jl, Weaver DJ, Weinstein SH, Grimes EM: Scrotal temperature and semen quality in men with and without varicocele. Arch Androl 1990, 24:215-219.

31. Lerchl A, Keck C, Spiteri-Grech J, Nieschlag E: Diurnal variations in scrotal temperature of normal men and patients with varicocele before and after treatment. Int J Androl 1993, 16:195-200.

32. Jung A, Eberl M, Schill WB: Improvement of semen quality by nocturnal scrotal cooling and moderate behavioural change to reduce genital heat stress in men with oligoasthenoteratozoospermia. Reproduction 2001, 121:595-603. 
33. Jung A, Schill WB, Schuppe HC: Improvement of semen quality by nocturnal scrotal cooling in oligozoospermic men with a history of testicular maldescent. Int J Androl 2005, 28:93-98.

34. Waites GM: Thermoregulation of the scrotum and testis: studies in animals and significance for man. Adv Exp Med Biol 1991, 286:9-17.

35. Hjolland NHI, Bonde JPE, Jensen TK, Olsen J: Diurnal scrotal skin temperature and semen quality. Int J Androl 2000, 23:309-3 I8.

36. Hjolland NHI, Storgaard L, Ernst E, Bonde JP, Olsen J: The relation between daily activities and scrotal temperature. Reprod Toxicol 2002, 16:209-2।4.

37. Jung A, Leonhardt F, Schill WB, Schuppe HC: Influence of the type of undertrousers and physical activity on scrotal temperature. Hum Reprod 2005, 20: 1022-1027.

38. Bujan L, Daudin M, Charlet JP, Thonneau P, Mieusset R: Increase in scrotal temperature in car drivers. Hum Reprod 2000, | 5: | 355-1357.

39. Thonneau P, Ducot B, Bujan L, Mieusset R, Spira A: Heat exposure as a hazard to male fertility. Lancet 1996, 347:204-205.

40. Chia DJ, Boston BA: Childhood obesity and the metabolic syndrome. Adv Pediatr 2006, 53:23-53.

41. Partsch CJ, Aukamp M, Sippell WG: Scrotal temperature is increased in disposable plastic lined nappies. Arch Dis Child 2000, 83:364-368.

42. Grove GL, Grove MJ, Bates NT, Wagman LM, Leyden JJ: Scrotal temperatures do not differ among young boys wearing disposable or reusable diapers. Skin Res Technol 2002, 8:260-270.

43. Moller $\mathrm{H}$ : Testicular cancer risk in relation to use of disposable nappies. Arch Dis Child 2002, 86:28-29.

44. Kirchhoff C: Gene expression in the epididymis. Int Rev Cytol 1999, I 88: I 33-202.

45. Pera I, Ivell R, Kirchhoff C: Body temperature (37 C) specifically downregulates the mRNA for the major sperm surface antigen CD52 in epididymal cell culture. Endocrinology 1996 137:445|4459.

46. Sharpe RM: Pathways of endocrine disruption during male sexual differentiation and masculinisation. Best Pract Res Clin Endocrinol Metab 2006, 20:9I-II0.

47. Travison TG, Araujo AB, O'Donnell AB, Kupelian V, McKinlay JB: A population-level decline in serum testosterone levels in American men. J Clin Endocrinol Metab 2007, 92:196-202.

48. Hughes IA: How vulnerable is the developing testis to the external environment? Arch Dis Child 2000, 83:28I-282.

49. Jury JA, Frayne J, Hall L: Sequence analysis of a variety of primate fertilin alpha genes: evidence for non-functional genes in the gorilla and man. Mol Reprod Dev 1998, $51: 92-97$.

50. Ivell R, Pusch W, Balvers M, Valentin M, Walther N, Weinbauer G: Progressive inactivation of the haploid expressed gene for the sperm-specific endozepine-like peptide (ELP) through primate evolution. Gene 2000, 255:335-345.

Publish with Bio Med Central and every scientist can read your work free of charge

"BioMed Central will be the most significant development for disseminating the results of biomedical research in our lifetime. "

Sir Paul Nurse, Cancer Research UK

Your research papers will be:

- available free of charge to the entire biomedical community

- peer reviewed and published immediately upon acceptance

- cited in PubMed and archived on PubMed Central

- yours - you keep the copyright
BioMedcentral 